\title{
Experiencia y pensamiento del exilio en María Zambrano
}

\author{
Virginia TRUEBA \\ Universitat de Barcelona
}

\begin{abstract}
Este trabajo aborda el concepto de "exilio" como experiencia vivida y categoría de pensamiento en María Zambrano, y lo hace desde la perspectiva de la crítica a la modernidad que Zambrano emprende desde fecha temprana y radicaliza con el tiempo. El trabajo piensa también el concepto de "regreso", que en este caso resulta tan falaz como imposible, de acuerdo a la noción exílica de la existencia misma de la que participa la pensadora.
\end{abstract}

Keywords: María Zambrano, exilio, memoria, franquismo, pensamiento contemporáneo.

En 1939 empieza para Zambrano un exilio que se prolongará más de cuatro décadas, de 1939 a 1984. Se trata además de un exilio que transcurre por muchos sitios (París, La Habana, México, Puerto Rico, Roma, La Pièce...), con ninguno de los cuales Zambrano llega a identificarse plenamente. Ahora bien, Zambrano no solo padece el exilio sino que tiene también la capacidad de pensarlo y comprenderlo, de acuerdo a esa idea suya tan capital de que «pensar, lo que se dice pensar, debería ser, ante todo, descifrar lo que se siente», como escribe en 1964 en un artículo para Semana, la publicación de San Juan de Puerto Rico (Zambrano 20I4: 87). Aquí Zambrano está situada ya en un espacio que no es propiamente el de la filosofía hegemónica y que explica, entre otros muchos, su concepto de exilio como vamos a ver.

En este aspecto, un primer sentir en relación al exilio es el de la desposesión y el despojamiento de aquello considerado, en principio, como propio, algo que Zambrano empieza a experimentar el 25 de enero de 1939, cuando sale con su madre y su hermana por la frontera de la Junquera. Atrás queda lo que ha sido hasta el momento su mundo, incluida esa comunidad decisiva de amigos y maestros, ahora ya asesinados como Federico García Lorca, o encarcelados como Miguel Hernández, o exiliados como José Ortega y Gasset, o a punto de serlo. Este último es el caso de Antonio Machado, que sale de España el mismo día que Zambrano pero por Portbou -en los pocos días que le quedan de vida escribirá, entre otros, este verso: «Ya solo reza el corazón, no canta» y aquel que pasa por ser el último y definitivo: «Estos días azules y este sol de la infancia»-. A Portbou llegará en unos meses, por cierto, en viaje inverso, Walter Benjamin -cuyo pensamiento tanto tiene que ver con el de Zambrano-, huyendo en su caso de los nazis. 
En breve, Zambrano tiene que enfrentarse a uno de los acontecimientos más duros de su exilio y en el que convergen, como para tantos exiliados españoles, los desastres de las dos guerras, la civil y la mundial: oficiales de las SS en París entregan a las tropas franquistas, después de torturarlo, a Manuel Muñoz, Director General de Seguridad de la II República y compañero entonces de Araceli, la hermana de Zambrano, torturada también. El trauma permanecerá ya para siempre, como ha recordado en un bellísimo texto autobiográfico aparecido en 2010, precediendo una antología de textos de Zambrano, Esencia y hermosura, José-Miguel Ullán, perteneciente a esas otras generaciones de exiliados que siguieron a la de Zambrano. Acompañado de José Angel Valente, Ullán empieza a visitar a ambas hermanas en La Pièce en 1968. Será más tarde cuando recuerde a Araceli como a aquella mujer sin presente, retenida en un pasado desde el cual solo es capaz de repetir «están a punto de regresar los mismos torturadores de antaño» (Ullán 20Io: 3I). Lo decisivo será que, a partir de todas aquellas circunstancias terribles de los primeros años cuarenta, las dos hermanas empiezan a sentirse auténticas enterradas vivas, lo que explica la identificación cada vez mayor con la figura de Antígona. «¿Sirvió de algo perder?», recuerda también Ullán que se preguntaba con frecuencia Araceli. Las reflexiones de Zambrano sobre la experiencia del exilio son, en cierto modo, la (imposible) respuesta.

La fecha de 1945 es importante, por otro lado, para todo el exilo republicano que asiste esperanzado al fin de la guerra pero atónito al mismo tiempo ante la persistencia de la dictadura franquista. Es entonces cuando la idea del regreso, a la que Zambrano dedicará una atención especial, empieza a alejarse del horizonte. En poco tiempo, en 1950, y a instancias de EE.UU., la ONU deroga el acuerdo de aislamiento diplomático que se había impuesto a España desde 1946. Para muchos exiliados este es un golpe definitivo, entre ellos para Eugenio Imaz, que acaba con su vida en I95I cuando entiende la irreversible complicidad del mundo futuro entre dictadura y democracia. Una convicción similar es la de Zambrano, que hubiera podido afirmar entonces y mucho después, como hizo José Ángel Valente en 1984 respondiendo a la pregunta de un periodista acerca de cómo escribir poesía después de Auschwitz, que el problema verdadero es que «no estamos aún después de Auschwitz». Los poco conocidos textos de Zambrano sobre Kafka aparecidos en publicaciones diversas (Espuela de Plata, I94I, Asomante, I957 y en el libro El sueño creador, 1965) desmienten esa esperanza que siempre se asocia a su pensamiento: en ellos Zambrano llama a Kafka «profeta del futuro» por su lucidez a la hora de desvelar el «infierno» (palabra clave en Zambrano) del mundo contemporáneo que no es otro que el derivado de aquella complicidad que a Imaz le cuesta la vida, y que Zambrano remonta, por otra parte, a los orígenes de una modernidad que se nutrió de una razón, no devenida sino nacida ya directamente como razón instrumental. 
Con el carácter irreversible que empieza a tener el exilio hay que relacionar un cierto punto de inflexión en el pensamiento de Zambrano, quien con el tiempo irá considerando el exilio cada vez más como aquella experiencia que toca algo decisivo de lo que somos, más allá de la circunstancia histórica que obligaría, lamentablemente, a enfrentarlo. Me inclino a hablar de un cierto punto de inflexión porque antes de que a Zambrano se le imponga la realidad definitiva del exilio, su pensamiento apunta ya a una dirección similar. Esto explica, por ejemplo, la distancia con Ortega desde fecha temprana, al menos desde 1934, cuando tiene lugar la anécdota recordada tantas veces: el reproche del "maestro" en su despacho de Revista de Occidente por no haber llegado aún a donde había que llegar (se entiende, a donde él mismo había llegado), y sin embargo pretender ya irse lejos. En esto último Ortega tiene razón, Zambrano se va lejos, la cuestión es a dónde.

Aquí debe recordarse que si el de Ortega es aún un pensamiento de signo ilustrado, convencido de las virtudes de una determinada racionalidad gracias a la cual podríamos salvarnos de nuestra condición de náufragos en el mar de la existencia (de acuerdo a las propias metáforas orteguianas), Zambrano sale del foco de esas luces para adentrarse en las mismas sombras que proyectan, es decir, en lo que esa racionalidad no ha alcanzado a pensar -tal vez, y esta es la clave, en lo no pensable-. El de Zambrano es, en este sentido, un pensamiento de los límites, que invita a cerrar los ojos para ver, para acceder a ese saber sobre el alma, como ella lo denomina, y que a Ortega le debió parecer de lo más oscuro. Ahora bien, es ese saber el que hace de Zambrano alguien que, a mi modo de ver, nos interpela de manera más directa. Lo mismo que su escritura, que sentimos cercana precisamente por menos argumentativa, por menos conclusiva, por más atenta a la discontinuidad o a lo fragmentario del pensamiento, escritura errante, exílica en cierto modo -algo a lo que también contribuyeron, y no hay que olvidarlo, las circunstancias del mismo exilio, la carencia de un marco estable de trabajo, de una habitación, de una biblioteca.

Si una figura representa en la obra de Zambrano esa escritura y ese saber es Antígona, la muchacha que descubre, no desde la luz y la claridad, sino desde el mundo de sombras que habita, una desnudez que no es coyuntural sino definitiva, la de la misma existencia una vez despojada de todo aquello con lo que solemos figurárnosla, para hacerla sostenible a la mirada y... pensable. Es esa desnudez la que busca iluminar, en este aspecto, la "razón poética" o creadora, la aportación sustancial de Zambrano al pensamiento contemporáneo, una razón a la que también podría denominarse con Chantal Maillard "débil", lo que no quiere decir claudicante sino con capacidad de adentrarse en ese territorio incierto (y en último extremo, abismático) al que la razón "fuerte" no pudo nunca asomarse, el de sus propios abismos. De ahí que afirme también Maillard que esa razón débil es, en verdad, fuer- 
te en su potencialidad -igual que la razón fuerte es débil en su rigidez y en su impotencia (I998: 27I).

Es también por su dimensión de mediación con esos abismos por lo que Zambrano se refiere en El hombre y lo divino (I955) a esa razón como "piadosa", porque sabe «tratar adecuadamente con lo diferente, con lo que es radicalmente otro que nosotros», afirma (20II: 227). Aquí deben considerarse dos cuestiones. Por un parte, el adverbio, adecuadamente, indicativo de un trato -es el sentido que tiene en Zambrano- que no asimila, que mantiene una cierta distancia con lo otro. Luego volveré a ello porque tiene una especial relevancia en una reflexión de Zambrano en I96I precisamente sobre el exilio. Luego está la cuestión de qué sea eso otro a lo que debe tratarse adecuadamente. Pues bien, eso otro apunta en parte a lo no pensable en el sentido mencionado arriba, pero también a una figura clave para entender el pensamiento en conjunto de Zambrano, que es la del vencido (que no la víctima exactamente, cuya pasividad le restaría dimensión política). Vencido es el idiota, el loco, la mujer, esa estirpe de desheredados, fracasados, exiliados a la que también Zambrano se siente pertenecer. Aquí se impone de nuevo la figura de Antígona en la particular lectura de Zambrano, como síntesis de esa estirpe: figura por excelencia de la otredad, lo mismo que de la razón poética que tiene también, y hay que subrayarlo, una raíz política, pues ha nacido como respuesta a la guerra y a los totalitarismos, a ese «funcionamiento fascista de la inteligencia» como lo denomina la misma Zambrano en Los intelectuales en el drama de España (I937), consistente en reducir y asimilar toda diferencia al principio de identidad (I998: 94). "¿Y no se habrá querido para eso el todo: para poder ser poseído, abarcado, dominado?», pregunta también Zambrano en otro texto de entonces, Filosofía y poesía de I939 (I987: 24).

En resumen, y volviendo a aquel cierto punto de inflexión que supone en el pensamiento de Zambrano la irreversibilidad del exilio, no es la imagen del náufrago orteguiano luchando por salvarse en un mar embravecido con la que se identifica Zambrano sino con la del exiliado perdido..., perdido en un desierto, ya sin circunstancias, donde el agua ha sido tragada y donde toda salvación se hace imposible. La imagen del desierto es también muy poderosa en una escritora cercana a Zambrano, la brasileña Clarice Lispector. En La pasión según G. H. (I964), la narradora explica que al nombrar, y por tanto, ordenar las cosas (como le gustaría a Ortega), al hacerlas suyas, al humanizarse, en suma, se había librado del desierto, sí, «pero también lo había perdido», añade (Lispector I988: 80). Perder el desierto es perder precisamente esa condición de im-pensable (de in-apropiable) que tiene la existencia una vez despojada de las representaciones más o menos confortables con que se la ha figurado, condición imposible de salvar y ni siquiera deseable, pues es ahí donde se juega todo. 
La imagen del desierto en Zambrano tiene mucho recorrido, y es especialmente importante en su reflexión sobre el exilio, asociado finalmente a un no-lugar, es decir, al desierto mismo. Es precisamente la cuestión del lugar la que permite a Zambrano en Los bienaventurados (I99I) diferenciar la figura del "exiliado" de las que denomina "refugiado" y "desterrado". El refugiado es aquel que, perdido su lugar, encuentra otro donde poder vivir, «se ve acogido [...] en un lugar donde se le hace un hueco, [...] se le ofrece y aún concede y, en el más hiriente de los casos, donde se le tolera» (Zambrano 2004: 3I). La figura del refugiado respondería también para Carlos Beorlegui, quien ha estudiado el exilio republicano siguiendo el análisis de Zambrano, a lo que José Gaos denominó "transterrado" o Juan Ramón Jiménez, "conterrado". América para ellos fue una especie de segunda patria en la que, con más o menos dificultades, se integraron, algo para lo que fue determinante el tema idiomático (en el caso de Juan Ramón) y el hecho de haber encontrado (el caso de Gaos) en el México de Lázaro Cárdenas los ideales de la España republicana perdida, algo que, sin embargo, le valdría a Gaos los reproches de Adolfo Sánchez Vázquez, quien considera que Gaos idealiza la América hispana, al ignorar lo que tiene también de autoritaria y caudillista (Beorlegui, 2004). En cuanto al "desterrado", es aquel que no acaba de integrarse en otro sitio porque sigue sintiéndose del lugar del que proviene: «se siente sin tierra, la suya, y sin otra ajena que pueda sustituirla. El encontrarse en el destierro no hace sentir el exilio, sino ante todo la expulsión», afirma Zambrano (2004: 32). Aquí no hay sustitución posible, por lo tanto, aunque sigue habiendo un lugar, el de origen, recordado desde la nostalgia. Sería el caso de José Ortega y Gasset o de Adolfo Sánchez Vázquez, en el análisis de Beorlegui.

Lo que debe retenerse de la clasificación de Zambrano es que tanto el refugiado como el desterrado mantienen el vínculo con un lugar. Todo lo contrario del exiliado, que no acaba de arraigar de nuevo y tampoco puede regresar a ninguna parte, ni siquiera desde la nostalgia. Zambrano afirmaba con rotundidad a principios de los años sesenta que «del exilio no se puede volver» (2014: 55), y ello no porque hayamos perdido el lugar propio al que pertenecíamos sino porque, en realidad, ese lugar nunca existió. Esto es lo que de algún modo Zambrano descubre en el exilio, nuestra condición de être en partance, en expresión francesa recordada por Cristina Rodríguez Marciel en un escrito sobre Jean-Luc Nancy y su idea de la existencia exiliada (20I4: 49), tan cercana, a su vez, a Zambrano, como ha estudiado por su parte Begoña Saez (2013). Lo que a Zambrano se le confirma en el exilio, por lo tanto, es que somos seres destinados a la partida, que partimos todo el rato de los lugares que habitamos, de los tiempos a los que pertenecemos, de nosotros mismos. Lo que se toca en el exilio es, en este aspecto, la existencia 
desnudada de las certezas con que nos la hacemos presentable, pensable. Lo in-fundamentado también de las verdades que nos sostienen.

Y este es, por otra parte, el motivo por el que se evita mirar al exiliado de frente, como lamentará la misma Antígona, que reconoce que nadie les ve, a ella y a su padre, Edipo, que nadie está dispuesto a aceptar ese "don" que es lo único que pueden ofrecer: el de su misma desnudez. El último monólogo de La tumba de Antígona no puede ser más diáfano:

Creían que íbamos pidiendo porque nos daban muchas cosas, nos colmaban de dones, nos cubrían, como para no vernos, con su generosidad. Pero nosotros no pedíamos eso, pedíamos que nos dejaran dar. Porque llevábamos algo que allí, allá, donde fuera, no tenían; algo que no tienen los habitantes de ninguna ciudad (Zambrano 20I2: 227).

El don de la desnudez, ese don que produce miedo, del que se teme el contagio, de ahí la inmunidad que se fabrica todo el rato frente al otro. La conclusión de todo esto es que al exiliado se le mira pero no se le ve, tal vez porque «aquel que lo vea acaba viéndose», como sostiene Zambrano (2004: 33), y quizás nadie está dispuesto a verse en la condición indigente y precaria (vulnerable, en el sentido también de Judit Butler).

Nadie está dispuesto a verse en ese espejo ni a entender que solo desde ahí podría fundarse la única comunidad posible, que nada tendría que ver con una comunidad de propietarios, como la denominaría Roberto Espósito, sino tal vez con una comunidad de exiliados, como afirmaría Zambrano, es decir, de aquellos que comparten lo único que poseen (lo único que se posee siempre): la carencia, la que no es subsanable. La poeta argentina María Negroni escribe en su último libro, Archivo Dickinson (2018) unos versos concentrados que recogen bien este pensamiento: «Poseer es imposible. Ese es el premio». Esto mismo es lo que enseña el exilio a Zambrano. Y es desde ahí que debe entenderse también el polémico artículo que escribe poco después de regresar a España titulado «Amo mi exilio» (I989), donde afirma: «yo no concibo mi vida sin el exilio que he vivido» (Zambrano 2009: 66).

En conclusión, Zambrano no lee el exilio en términos de despojamiento de lo propio, aunque en un principio ese pudiera ser el sentir. Se separa en ese aspecto del modelo judeo-cristiano (donde la errancia se rectificará finalmente) o del modelo griego (donde el regreso a casa es un destino, como en Ulises), caminos ambos prototípicamente occidentales en el sentido de que siempre regresan a lo mismo, a lo que se mantiene idéntico, a lo no susceptible de cambio, precisamente aquello que en Zambrano queda problematizado. Puede entenderse ahora su expresión en La Pièce: «exilio logrado». Me parece importante que sea allí, no en París, ni en La Habana, ni en Roma... las grandes ciudades en que ha vivido, sino en una pequeña cabaña / choza / catacumba / gruta / madriguera (como recuerda José-Miguel Ullán 
que Zambrano llamaba a aquel lugar) en la montaña, en un espacio fronterizo entre dos países (Francia y Suiza), fuera de todo centro representativo, un no-lugar, donde Zambrano sienta el exilio en toda su amplitud, como quien ha visto de verdad, es decir, como quien ha visto no en la oscuridad y por tanto a pesar de la oscuridad, sino como quien se ha dejado invadir por la oscuridad e iluminar por ella.

Ahora bien, junto a la reflexión sobre el no-lugar del exilio, Zambrano piensa también el tiempo, ese tiempo intempestivo del exilio en relación en este caso a las nociones de historia y de memoria. Es, en este aspecto, como si el exilio la hubiera mantenido en un tiempo desencajado respecto del tiempo presente, en un tiempo distinto al de esa Historia que, especialmente desde la modernidad, avanza lineal, continua, hacia adelante, en progreso siempre. No obstante, lo que comprende Zambrano en el exilio es que el desencaje del tiempo está ocurriendo, en realidad, siempre, esto es, que no pertenecemos a un tiempo solamente, que hay cosas que están pasando todo el rato. Por eso no es exactamente el tiempo de la Historia el que se despliega en sus textos sino el de una memoria en la que convergen tiempos distintos. Es lo que ocurre, por ejemplo, en esa particular autobiografía, escrita a principios de los cincuenta, titulada Delirio y destino. Los veinte años de una española, donde Zambrano evoca los años anteriores a la llegada de la República, con la intención de no olvidarlos, sí, pero sobre todo de narrarlos de otro modo, desde otras coordenadas, abriendo la temporalidad del relato histórico para integrar en él lo que ella misma describe en términos de un "sueño", que se habría hecho realidad el I4 de abril de I93I pero en el que desembocarían, a su vez, otros muchos sueños (los de las pinturas de Velázquez, los artículos de Larra o las novelas de Pérez Galdós). Ese es el pasado, entiende Zambrano, que debe resistir la tentación, ya no solo de olvidarse, sino también de narrarse con la única finalidad de archivarse y darse por saldado/salvado.

De los diferentes textos que escribió Zambrano sobre la cuestión del tiempo y sus relaciones con la historia y la memoria, quisiera destacar uno en concreto por su relación directa con el exilio. Se trata de un texto de especial dureza, publicado en París en I96I, en Cuadernos del Congreso por la Libertad de la Cultura, titulado "Carta sobre el exilio». Para esa fecha algo se mueve en España, el asunto es qué exactamente. Por una parte, son años en que se ha reanudado un cierto diálogo con el exilio, algo de lo que dan fe las publicaciones periódicas donde los nombres de (algunos) exiliados tienen ya una presencia. Sin ir más lejos, hay que recordar que en 1966 ven la luz los dos primeros artículos sobre Zambrano: el de José Luis Aranguren en Revista de Occidente («Los sueños de María Zambrano») y el de José Ángel Valente en Ínsula («El sueño creador»). En otro orden de cosas, son años en que el régimen, en pleno lavado de cara frente a la comunidad internacio- 
nal, permite el regreso de ciertos exiliados, niños de la guerra sobre todo. Ahora bien, no solo es el régimen el que anima a la vuelta, y aquí empieza a tocarse el asunto que afecta a Zambrano, también lo hacen aquellos a los que Zambrano llama en su carta "antifranquistas". No debe olvidarse que aquellos fueron también años de cierta agitación política en sectores tan diversos como la minería, la universidad o, lo que más debió descolocar al núcleo duro del franquismo, entre ciertos sectores católicos. Zambrano no se siente interpelada ni por unos ni por otros, aunque sí se ve obligada a responder, no al régimen como es obvio, sí a los antifranquistas. Lo interesante entonces de su escrito es, a mi modo de ver, la conciencia lúcida de lo que acabaríamos conociendo años más tarde, ya en democracia, como pacto de olvido. Esto es lo que se mueve en ese momento en España para Zambrano, un pacto de olvido que tiene que ver con la dimensión conservadora de cierto antifranquismo, como tuvo después también desde una perspectiva similar la transición y los sucesivos gobiernos que fueron llegando.

Aquí entiendo por dimensión conservadora aquella apoyada en una construcción de la historia que reclama, ya no exactamente el olvido sino un relato del pasado que permita la clausura del mismo en el archivo de la memoria. Lo que Zambrano lamenta en I96I es precisamente esa actitud, el intento de borradura del pasado de acuerdo a ese deseo de los antifranquistas de que cesara de haber exiliados. "Ahora ya apenas al exiliado se le pregunta nada» lamenta Zambrano (20I4: 8), quien cuestiona asimismo el origen de esa historia de la que los antifranquistas se sienten relatores (casi notariales), la que empezaría en la precisa fecha de i939. En este aspecto, si la República no empezó para Zambrano propiamente en I93I como expone en Delirio y destino, tampoco 1939 es para ella fundadora de nada, más bien al contrario, ese año es el que abre el camino de un exilio cuya enseñanza esencial es precisamente la de la ilusión de toda idea de propiedad. El regreso a España, entiende entonces, tendría el precio de asimilarse a esa historia en marcha que no quiere mirar atrás, y esta es la clave para entender la contundente respuesta de Zambrano en la carta:

Los exiliados de la primera hora -afirma- no somos, por escandalosa y ambigua que esta afirmación pueda sonar, antifranquistas. ¿Cómo podría ser esa nuestra definición? [...] Éramos habitantes de aquella España sumergida. De ella fuimos despeñados, lanzados en todo caso. Y hoy somos sus supervivientes (Zambrano 20I4: 29).

Lo decisivo en Zambrano, y esto desde una óptica tanto política como existencial, es que el pasado constituye una dimensión de la vida presente, y no puede (ni debe) dejar de serlo.

El reproche por no querer asimilarse lleva implícito algo que también Zambrano ha vivido de manera dolorosa y que puede rastrearse en dife- 
rentes textos: la acusación, manifestada con frecuencia en forma de interrogación directa, de mantenerse al margen. Es lo que siente Antígona ante Creonte (recordemos que Creonte pide a Antígona que regrese a la ciudad, que salga de su exilio en la tumba, olvidando toda la violencia anterior que él mismo ha causado), o Juana de Arco (otra figura del imaginario de Zambrano) ante los jueces de su proceso, o Miguel de Molinos ante los del suyo, o el poeta cubano Calvert Casey, homosexual, ese hombre que tan solo pedía, escribirá Zambrano en 1982 después de su suicidio en Roma, «no ser interrogado» (Zambrano 2007: 225). La interrogación es también la que siente la propia Zambrano cuando un periodista le pregunta en 1937 que por qué vuelve a España desde Chile si la guerra está perdida, a lo que ella responde que precisamente por ello. O, ya al regresar a España en 1984, cuando se le pregunta por qué no menciona nunca la muerte de Franco, como reprochándole no sentirla lo suficiente -lo que Zambrano recuerda, especialmente entristecida, en un artículo de Diario I6 del I7 de noviembre de 1985 (Zambrano 2009: IO9-IIO).

La invitación a regresar, por lo tanto, de los antifranquistas tiene para Zambrano poco de hospitalidad y mucho de hostilidad, esas dos palabras de las que Jacques Derrida sostuvo en los años noventa que están contaminadas etimológicamente. Abrimos nuestras casas, nuestras fronteras (cuando las abrimos) pero siempre a cambio de otra cosa, de que aquel que entra (el otro) se adapte a nuestras costumbres, aprenda nuestra lengua, etc. Ninguna razón piadosa ha actuado aquí, también podría haber dicho Zambrano, ningún trato adecuado con lo otro ha tenido lugar. Es lo que también siente ante la llamada de los antifranquistas, de ahí su lamento: «Solo reintegrándonos a la España de hoy, a su tierra o a su momento histórico, a su presente, podemos convertirnos propiamente en antifranquistas. Es decir, al perder nuestra condición de exiliados. ¿Es eso quizá lo que se nos pide? ¿Dejar de ser exiliados para ser antifranquistas? Quizás sea eso» (Zambrano 20I4: 29).

Por otra parte, la consecuencia última de que el fin de la dictadura solo se esté concibiendo al margen del pasado es que el enfrentamiento no termine nunca. Se busca ahora «eliminarnos del pasado como hace más de veinte años se nos arrojó del porvenir que creyeron comenzaba", afirma Zambrano (20I4: 30). No es que el olvido, en forma de archivo clausurado, no garantice el futuro sino que lo determina negativamente en tanto el "pasado condenado [...] se convierte en un fantasma. Y los fantasmas ya se sabe, vuelven» (Zambrano 20I4: I2). Este es el diagnóstico del que partía precisamente el libro de Teresa Vilarós en 1998, El mono del desencanto, el primero en leer el fin de la dictadura y la transición desde un lugar menos complaciente que el habitual. En 196I Zambrano expone ideas similares, entre ellas la muy benjaminiana de que la única esperanza será la que provenga del pasado, no del futuro, de ahí la necesidad de redimir a los que nos precedieron, no a los que 
vendrán. Es de ellos, de los que nos precedieron, de los que derivará la única paz posible, de «los muertos, de los enterrados y semienterrados vivos» (Zambrano 20I4: 3I), de alguien como Antígona, cuyo delirio nos enfrenta precisamente a la voz de ese vencido que no ha muerto.

Muchos exiliados republicanos (cerca de la mitad) nunca regresaron. Zambrano lo hace, aunque no inmediatamente después de la muerte de Franco sino en 1984, lo que demuestra que el tema no era Franco, ni el franquismo exactamente. El regreso de alguien como Zambrano fue importantísimo para todos aquellos que ya la conocían, o que estaban empezando a conocerla, o que la descubrieron entonces. Miguel Morey ha contado que en 197I descubrió en una librería de lance de Barcelona las Obras reunidas (en la editorial Aguilar) de una tal María Zambrano de la que nada sabía, ni siquiera que en 1938 había impartido clases en la misma Facultad de Filosofía en la que él estaba estudiando. Explica Morey que comprar aquel volumen tuvo mucho que ver con la «nostalgia por los maestros que nunca llegamos a tener [...] suplantados por pálidos sucedáneos», y tuvo mucho que ver con «la rabia también», añade (Morey 20I0: 17). Esencial, por lo tanto, el regreso de alguien como Zambrano.

Ahora bien, han sido muchos, entre ellos el mismo Morey, los que han reconocido algo en relación a ese regreso de Zambrano que me gustaría subrayar. Se produce entonces una profusión de actos, homenajes, publicaciones en torno a Zambrano. La España democrática ha echado a andar y de algún modo necesita proveerse de relatos que la sustenten y, en este aspecto, los construidos en torno a los exiliados resultaron decisivos. El de Zambrano fue uno de ellos, un relato que acaba transformándola en algo contra lo que ella precisamente luchó siempre, el personaje, olvidándose en parte (otra vez el olvido) una filosofía, la suya, a la altura de la de algunos de los grandes pensadores contemporáneos.

Es esa recepción de Zambrano al regresar a España la que merece ya un estudio pormenorizado. Lo interesante sería una lectura crítica del marco cultural que se dio a sí misma la izquierda en el poder. De acuerdo a la nueva lógica (ya de mercado, no hay que olvidarlo, como bien sostenía Teresa Vilarós), muchos de los exiliados pasaron a ser «de los nuestros», de acuerdo a aquel espíritu asimilacionista que lamentaba la misma Zambrano en 196I. Habría que analizar también cómo esa izquierda se apropió de cierto pasado mientras ignoró, cuando no combatió, una disidencia viva, como ha estudiado por su parte Germán Labrador (20I7) en un libro que viene a actualizar los anteriores planteamientos del libro de Vilarós.

Que España sigue teniendo una grave dificultad para escribir su historia es una realidad incontestable. En cuanto al exilio, es verdad que la izquierda política, social y cultural lo ha reconocido como un drama que no debería repetirse y que por ello mismo no debería olvidarse, pero también lo es su 
empeño en negarlo como hecho presente, que nos sigue hablando, por ejemplo cada vez que quedan al descubierto las grietas de la propia democracia. Lo que me parece importante en relación a Zambrano y su pensamiento sobre el exilio es que no constituye meramente un objeto de estudio que nos atañe abordar a hora como investigadores de nuestro pasado, sino que se trata de un pensamiento que interpela nuestro presente y que por ello mismo puede servirnos para pensar la oportunidad de que la política se deje atravesar de una vez por todas por la potencia de la vida, en lugar de imponerse a ella. Un reciente artículo de Antolín Sánchez Cuervo (2019), uno de los principales conocedores del pensamiento del exilio en Zambrano, apunta en esta dirección. Se titula precisamente «María Zambrano y la crítica de la razón democrática». En un momento de cierto colapso de nuestras democracias, un pensamiento como el de Zambrano tal vez pueda servirnos, entre otros, para emprender algunas reflexiones necesarias.

\section{Bibliografía}

Beorlegui, Carlos, «El exilio como reflexión filosófica: una sinfonía de acentos», Letras de Deusto, 34, I04, 2004, pp. 13-59.

Labrador, Germán, Culpables por la literatura. Imaginación política y contracultura en la transición española (I968-I986), Madrid, Akal, 2017.

Lispector, Clarice, La pasión según G. H., Barcelona, Muchnik Editores, 1988.

Maillard, Chantal, «Las mujeres en la filosofía española», en Breve historia feminista de la literatura española (en lengua castellana), V, La literatura escrita por mujer. Desde el siglo XIX hasta la actualidad, coord. Iris M. Zavala, Barcelona, Anthropos, I998, pp. 267-296.

Morey, Miguel, Monólogos de la bella durmiente. Sobre María Zambrano, Pamplona, Editorial Eclipsados, 2010.

Rodríguez Marciel, Cristina, «Ontología del abandono. Jean-Luc Nancy y la "existencia exiliada"», Aurora, I5, 20I4, pp. 46-55.

Saez Tajafuerce, Begoña, «El exilio en lo propio según Jean-Luc Nancy y María Zambrano», Aurora, I4, 2013, pp. 56-63.

Sánchez Cuervo, Antolín, «María Zambrano y la crítica de la razón democrática», Aurora, 20, enero-febrero 20I9, pp. IIO-I23.

Ullán, José Miguel (ed.), María Zambrano, Esencia y hermosura, Barcelona, Galaxia Gutenberg /Círculo de Lectores, 2010.

Valente, José Ángel, «Palabra y ritmos: el don de la lengua», Entrevista de J. Martín Arancibia, Quimera, 39-40, 1984, pp. 83-86.

Vilarós, Teresa, El mono del desencanto. Una crítica cultural de la transición española (1973-1993) [I998], Madrid, Siglo XXI, 2018.

Zambrano, María, Filosofía y poesía, Madrid, Fondo de Cultura Económica, 1987 . 
- Los intelectuales en el drama de España y escritos de la guerra civil, ed. Jesús Moreno Sanz, Madrid, Trotta, 1998.

-. Los bienaventurados, Madrid, Siruela, 2004.

-. El hombre y lo divino, Obras Completas, III, ed. Jesús Moreno Sanz, Barcelona, Galaxia Gutenberg / Círculo de Lectores, 201 .

-. Islas, ed. J. L. Arcos, Madrid, Verbum, 2007.

- Las palabras del regreso, ed. Mercedes Gómez Blesa, Madrid, Cátedra, 2009.

- La tumba de Antígona, ed. Virginia Trueba, Madrid, Cátedra, 2012.

-. El exilio como patria, edición, introducción y notas de Juan Fernando Ortega Muñoz, Barcelona, Anthropos, 2014. 